\title{
Presumptive sex chromosomes of a unisexual homomorphic species of lizards, Lepidodactylus lugubris
}

\author{
Vitaly Volobouev* and \\ Georges Pasteur
}

Laboratoire de Génétique Ecologique, Ecole Pratique des Hautes Etudes, place Eugène-Bataillon, 34060 Montpellier, France.

Incorporation of 5-bromo-2'-deoxyuridine (BrdU) in prometaphasic chromosomes allows active from inactivated $X$ chromosomes in female mammalian cells to be distinguished. We have applied the technique to the all-female, chromosomally homomorphic gecko Lepidodactylus lugubris. Similar differences to those obtained between the two female sex chromosomes of mammals are observed in the patterns of chromosome pair 1 . It is argued that this is more likely to reflect incipient $\mathrm{ZW}$ heterogamety than female (XX) homogamety.

\section{INTRODUCTION}

During the last fifteen years, considerable progress has been achieved in mammalian chromosome analysis, due to developments in methods of differential chromosome staining (see Benn and Perle, 1986; Dutrillaux et al., 1986a). While karyotypes of about 20 per cent of mammalian species have now been studied using one or more such banding techniques, and some mammalian groups have been investigated in great detail, including phylogenetic reconstructions (see Dutrillaux et al., 1986 ; Couturier and Dutrillaux, 1986; ViegasPéquignot et al., 1986), other vertebrate classes lag far behind in this field. This is especially true with reptiles. Although there are more than twice as many species of reptiles than mammals in presentday nature, only a few tens have been investigated by chromosomal G-, C- or N-banding (Bickham, 1984; Moritz and King, 1985). However, reptiles present considerable interest for evolutionary cytogenetics, as they allow us to trace virtually all stages in the formation of the various types of sex determination chromosomal mechanisms (Bull, 1983; Jones and Singh, 1985) and they offer repeated instances of thelytokous parthenogenesis, associated with some alteration or other of the meiotic process (see Darevsky et al., 1985).

We have started to apply to the parthenogenetic gecko Lepidodactylus lugubris, a species of the

\footnotetext{
* Present address: U.A. 6320 du CNRS (Structure et Mutagenèse Chromosomiques), Institut Curie, 26 rue d'Ulm, 75231 Paris 05.
}

Pacific area, one of the high-resolution banding techniques (Viegas-Péquignot and Dutrillaux, 1978) elaborated for mammalian chromosomes. Briefly, this technique is based first on obtaining prometaphasic chromosomes by cell culture synchronization, and secondly on inducing the formation of R-bands by 5-bromo-2'-deoxyuridine (BrdU) incorporation. In mammals, this has allowed identification of sex chromosomes in the homogametic sex because of different replication patterns: the inactive $X$ chromosome exhibits late replication in comparison with the active one. In lower vertebrates, comparable methods have allowed detection of nascent heterogamety, either male as in the case of Rana esculenta (Schempp and Schmid, 1981) or female as in the fish species Poecilia sphenops (Haaf and Schmid, 1984), among chromosome pairs that were all homomorphic after both conventional cytogenetic staining and standard banding techniques.

\section{MATERIAL AND METHODS}

Chromosome analyses were carried out on preparations obtained from fibroblast cultures established after tail biopsies performed on individuals from our stocks 5 and 9, each stock being descended from one female collected in Tahiti, Society Islands, and on a further female (No.13) from the Mururoa atoll, Gambier Islands. The cells and explants were kept in liquid nitrogen. The lizards' fibroblasts were cultured in MacCoy 5a culture 
medium with 10 per cent calf foetal serum at 30 $32^{\circ} \mathrm{C}$. Beside the R-banding of prometaphasic chromosomes obtained with the technique of Viégas-Péquignot and Dutrillaux (1978), C-bands were obtained with that of Sumner (1972).

\section{RESULTS}

The diploid karyotype of Lepidodactylus lugubris is comprised of 22 acrocentric chromosome pairs of progressively decreasing size. Identification of individual pairs with standard Giemsa staining is virtually impossible (fig. 1), whereas each pair displays its own distinctive pattern after the highresolution banding technique (fig. 2). Fig. 2 shows that the largest pair is then heteromorphic with respect to size and banding pattern. Since this heteromorphism was found in every cell of the investigated females, we conclude, in reference to mammals and the similar cases known in lower vertebrates (see Introduction), that this heteromorphism is due to condensation asynchrony between chromosomes involved in sex determination.

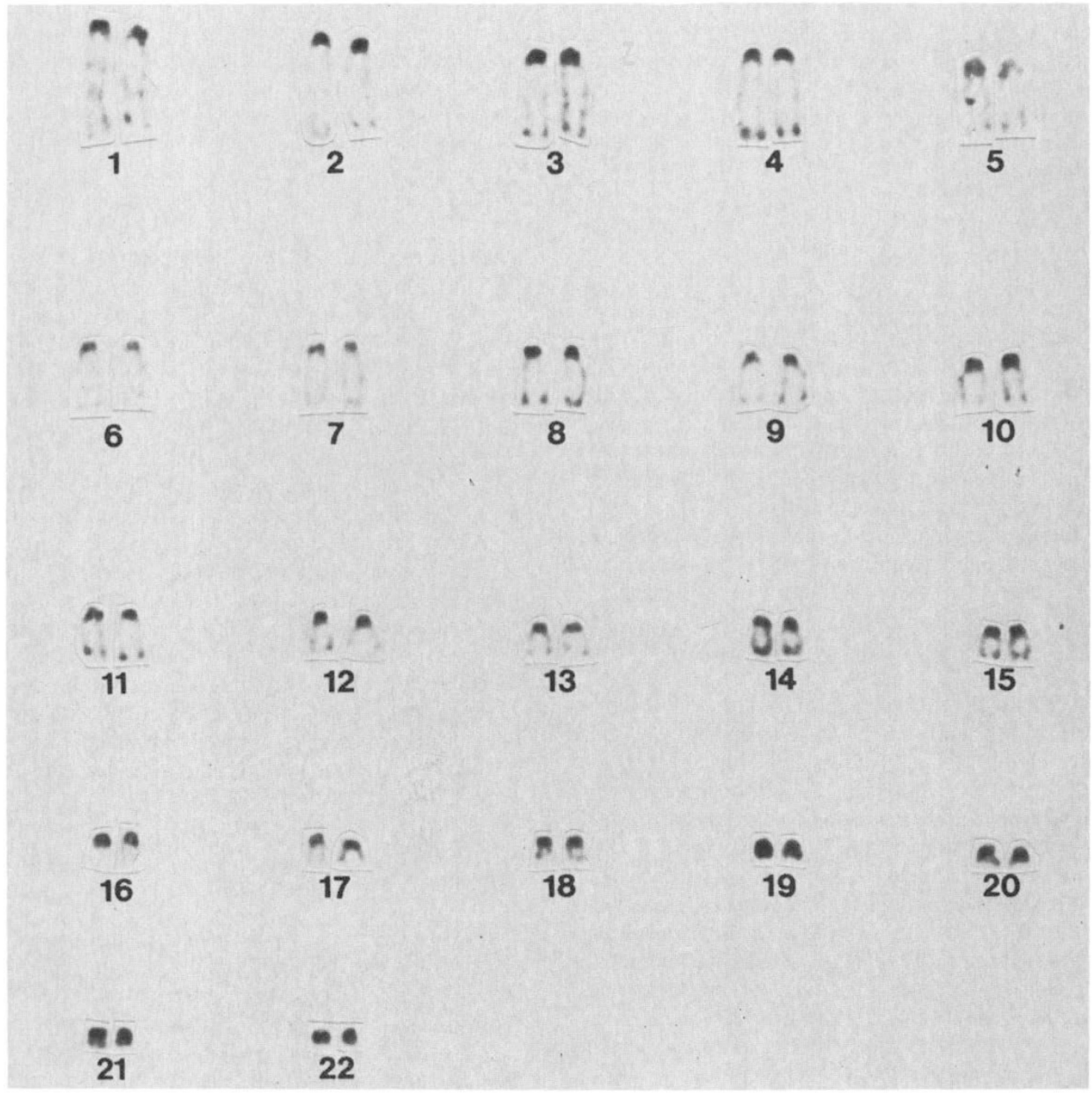

Figure 1 Standard Giemsa staining of the L. lugubris female karyotype. 
C-heterochromatin staining is illustrated in fig. 3: no heteromorphism is apparent in heterochromatin amount or distribution. Each chromosome pair possesses a pericentromeric block of heterochromatin slightly varying in size. In addition, some pairs have a small block of telomeric heterochromatin. The smallest four pairs are, due to their sizes, almost entirely heterochromatic. Cbanded karyotypes were similar in all specimens examined.

\section{DISCUSSION}

The chromosome set of Lepidodactylus lugubris was previously studied by Cuellar and Kluge (1972), who encountered only diploid specimens. The present standard karyotypes fully agree with their data. Triploids have been found in L. lugubris, and their chromosomes have been studied with the C-banding technique (King, Pasteur and Moritz, in preparation). Triploid heteromorphism has been
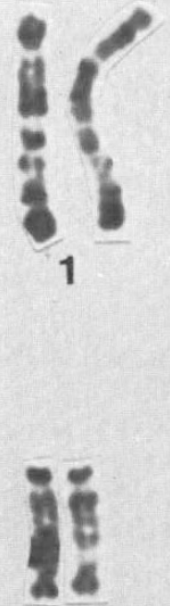

6

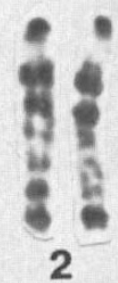

2

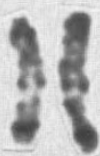

7

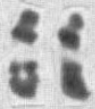

12

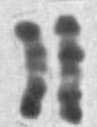

11

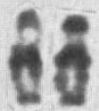

13

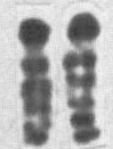

8

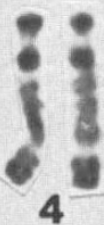

4

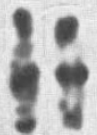

9

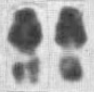

14

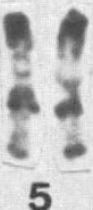

5

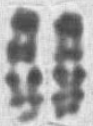

10

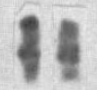

16

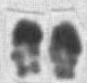

17

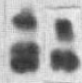

18

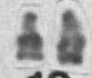

19
15
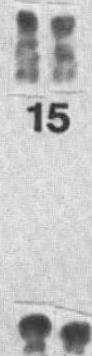

20

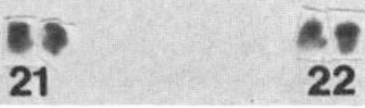

Figure 2 R-banded prometaphasic chromosomes of $L$. lugubris after synchronization by thymidine and 7-hour BrdU incorporation. 


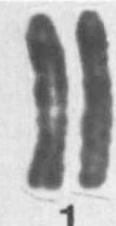

1

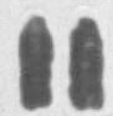

6

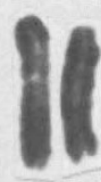

2

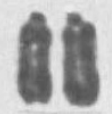

7

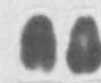

12

11
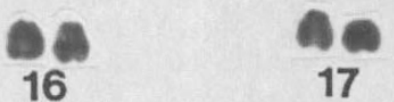

17
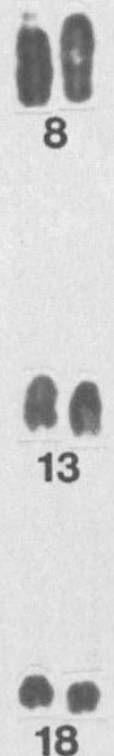

8

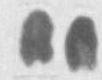

13
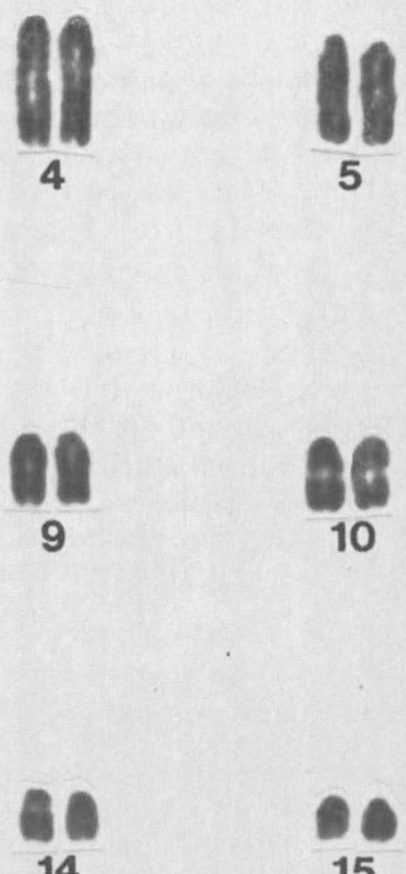

15
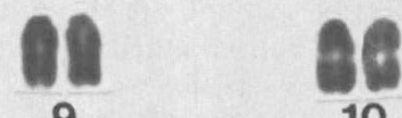

10

14
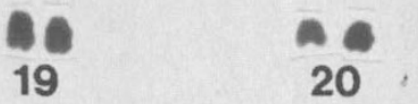

revealed, in the form of a large pericentromeric block of heterochromatin in one chromosome of the largest triad. King et al. (op. cit.) suppose that this heteromorphism is a result of the insemination of a diploid parthenogen by a male carrying the pericentromeric heterochromatic block.

In the present study, the observed differences between the two chromosomes of the first pair after BrdU incorporation reflect a replication time difference that, in mammals, is characteristic of sex chromosomes in the homogametic sex (see Introduction). The divergence, however, is some- what less pronounced here than in mammals: are chromosomes 1 of L. lugubris XX chromosomes too? If such were the case, then it would be the first known instance of vertebrate $\mathrm{X}$ chromosome inactivation outside the class of mammals. But males are not unknown in L. lugubris (see Pasteur et al., 1987): if the exceptional males were heterogametic, i.e., $\mathrm{XY}$, how could they originate from purely $\mathrm{XX}$ parents? It sounds more reasonable to suppose that we are in the presence of early heterogamety, comparable to the concealed $\mathrm{ZW}$ heterogamety observed by Haas and Schmid 
(1984) in Poecilia sphenops. We already know that the $\mathrm{W}$ chromosome of homomorphic $\mathrm{ZW}$ snakes strongly resembles the mammalian $\mathrm{X}$, in both mitotic cycle (Jones, 1984) and specific satellite DNA sequences (Jones and Singh, 1985). Clearly, investigation of at least one male L. lugubris karyotype with a technique of the kind used for the present study is required.

On the methodological side, this study shows that once long-term cell culture is mastered, a technique formerly developed in the investigation of mammals can be a method of choice for reptile cytogenetics. In view of the difficulties met with when using conventional techniques of G-, R- and Q-banding, the interest of techniques involving BrdU incorporation for chromosomal analyses cannot be overemphasized.

Acknowledgements We are most grateful to Eric Mathieu for providing the Mururoa specimen. The Tahiti stocks are due to collecting by Charles and Françoise Blanc. We thank Martine Lombard and Jean-Yves Quéro for valuable technical assistance, as well as Jérôme Couturier, Hélène Hayes and Nicole Pasteur for suggestions about the manuscript.

\section{REFERENCES}

BENN, P. A. AND PERLE, M. A. 1986. Chromosome staining and banding techniques. In Rooney, D. E. and Czepulkowski, B. H. (eds.) Human Cytogenetics: A Practical Approach, IRL Press, Oxford, pp. 57-84.

BICKHAM, J. W. 1984. Patterns and modes of chromosomal evolution in reptiles. In Sharma, A. K. and Sharma, A. (eds.) Chromosomes in Evolution of Eukaryotic Groups, Vol. 2, CRC Press, Boca Raton, Florida, pp. 13-40.

BUll, J. J. 1983. Evolution of Sex Determining Mechanisms. Benjamin/Cummings, Menlo Park, Carlifornia.

COUTURIER, J. AND DUTRILlauX, B. 1986. Evolution chromosomique chez les carnivores. Mammalia, 50, 124162.
Cuellar, O. AND Kluge, A. G. 1972. Natural parthenogenesis in the geckonid lizard Lepidodactylus lugubris. J. Genet., 61, 14-28.

DAREVSKY, S., KUPRIYANOVA, L. A. AND UZZELL, T. 1985. Parthenogenesis in reptiles. In Gans, C. (ed.) Biology of the Reptilia, Vol. 15, Academic Press, New York, pp. 411526.

DUTRIllauX, B., COUTURIER, J., MUleris, M., RUMPler, Y. AND VIEGAS-PÉQUIGNOT, E. 1986a. Relations chromosomiques entre sous-ordres et infra-ordres, et schéma évolutif général des primates. Mammalia, 50, 108121.

DUTRILlAUX, B., VIEGAS-PÉQUiGNOT, E. AND COUTURIER, J. 1986 b. Les méthodes cytogénétiques. Mammalia, 50, 11-20.

HAAS, T. AND SCHMID, M. 1984. An early stage of $\mathrm{ZW} / \mathrm{ZZ}$ sex chromosome differentiation in Poecilia sphenops var. melanistica (Poeciliidae, Cyprinodontiformes). Chromosoma, 89, 37-41.

JONES, K. W. 1984. The evolution of sex chromosomes and chromosomal inactivation in reptiles and mammals. In Ferguson, M. J. W. (ed.) Structure, Development and Evolution of Reptiles, Academic Press, London, pp. 305-316.

JONES, K. W. AND SINGH, L. 1985. Snakes and the evolution of sex chromosomes. Trends Genet., Feb. 1985, 55-61.

MORITZ, C. AND KING, D. 1985. Cytogenetic perspectives on parthenogenesis in the Gekkonidae. In Grigg, G. (ed.) Biology of Australian Frogs and Reptiles, Royal Zoological Society of New South Wales.

pasteur, G., AGNĖse, J. F., BlanC, C. P. AND PASTeur, N. 1987. Polyclony and low relative heterozygosity in a widespread unisexual vertebrate, Lepidodactylus lugubris (Sauria). Genetica, 75, 71-79.

SCHEMPP, W. AND SCHMID, M. 1981. Chromosome banding in amphibia VI. BrdU-replication patterns in anura and demonstration of $\mathrm{XX} / \mathrm{XY}$ sex chromosomes in Rana esculenta. Chromosoma, 83, 697-710.

SUMNER, A. T. 1972. A simple technique for demonstrating centromeric heterochromatin. Exper. Cell Res., 75, 304-306.

VIEGAS-PÉQUIGNOT, E. AND DUTRILlAUX, B. 1978. Une méthode simple pour obtenir des prophases et des prométaphases. Ann. Génét., 21, 122-125.

VIEGAS-PÉQUIGNOT, E., PETIT, D., BENAZZOU, T., PRUD'HOMME, M., LOMBARD, M., HOFFSCHIR, F., DESCAilleauX, J. AND DUTRrllauX, B., 1986. Phylogénie chromosomique chez les Sciuridés, Gerbillidés et Muridés, et études d'espèces appartenant à d'autres familles de rongeurs. Mammalia, 50, 164-202. 